\title{
Kearifan Lokal Sebagai Bentuk Kontrol Sosial Masyarakat Sukolilo
}

\author{
Riris Tiani \\ Fakultas Ilmu Budaya, Universitas Diponegoro \\ tiani.riris@gmail.com
}

\begin{abstract}
Tradition ceremony Meron one of the rituals held every month Maulud.This tradition is done by the people of Sukolilo village Pati which aims to commemorate the birthday one of Prophet. Data collection methods used were interviews and documentation analyzed using etnolinguistic theory.

Based on the analysis of local wisdom of the Meron tradition of Sukolilo society in Pati Regency, it can be concluded that the form of local traditions of Meron wisdom culture develops in the form of the traditional phrase which is realized in traditional ceremonial ritual and traditional feast, preserving traditional technology in this case through gunungan offerings architecture. While the function of the cultural tradition is 1) usage or how to perform a ceremony or ritual, 2) folkways or habits in living the tradition of ancestors that are still preserved, 3) norms or norms related to the custom known and obeyed by the community.
\end{abstract}

Keywords: local wisdom, tradition, Sukolilo

\section{Intisari}

Upacara tradisi meron salah satu ritual yang dilaksanakan setiap bulan Maulud. Tradisi ini dilakukan oleh masyarakat desa Sukolilo Kabupaten Pati yang bertujuan untuk memperingati hari kelahiran Nabi. Tujuan dari penelitian ini adalah untuk mendeskripsikan fungsi bentuk kearifan lokal. Metode pengumpulan data yang digunakan adalah wawancara dan dokumentasi yang dianalisis dengan menggunakan teori etnolinguistik.

Berdasarkan analisis kearifan lokal tradisi Meron masyakarat Sukolilo di Kabupaten Pati, dapat disimpulkan bahwa bentuk tradisi budaya local wisdom Meron berkembang dalam bentuk penyebutan ungkapan tradisional yang terealisasi dalam pertunjukan ritual upacara adat dan pesta adat, pelestarian teknologi tradisional dalam hal ini melalui arsitektur gunungan sesaji. Sedangkan fungsi dari tradisi budaya tersebut berupa 1) usage atau cara melakukan upacara atau ritual, 2) folkways atau kebiasaan dalam menjalani tradisi leluhur yang masih dilestarikan, 3) norm atau norma berkaitan dengan adat yang diketahui dan ditaati oleh masyarakat.

Kata kunci: kearifan lokal, tradisi, Sukolilo 


\section{Pendahuluan}

Duranti (1997) menjelaskan bahwa terdapat hubungan timbal balik antara bahasa dan budaya.Dengan mempelajari bahasa secara otomatis dapat pula dipelajari budaya yang terkandung di dalamnya. Sapir-Whorf (dalam Jourdan and Tuite, 2006) menjelaskan bahwa bahasa memiliki kekuatan dan dapat mengontrol pandangan masyarakat terhadap dunia. Bahasa menjadi petunjuk dalam memahami peristiwa.Bahasa menjadi framework dalam memaknai dunia.

Sejalan dengan pernyataan Koentjaraningrat (2003) kebudayaansebagai bentuk manifestasi dari hasil berpikir yang meliputi sistem gagasan, rasa, tindakan, serta karya yang dihasilkan oleh manusia yang dipelajari dalam kehidupan bermasyarakat dan diwujudkan melalui secara nyata bahasa. Dalam khasanah keilmuan, penelitian yang mengembangkan bahasa dari aspek budaya di sebut dengan Antropolinguistik tetapi ada juga yang menyebutkan Etnolinguistik. Sibarani (2012) menjelaskan bahwa Anthropolinguistik is the study of language within the framework of anthropology, the study of culture within the framework of linguistic, and the study of other aspects of humankind within the interrelated framework of both anthropology and linguistics.Kebudayaan merupakan aspek yang paling dominan dalam kehidupan manusia, sehingga segala hierarki kajian bahasa dikaitkan dengan kebudayaan. Hakikat analisis dalam kajian etnolinguistik di antaranya: bahasa sebagai unsur lingual dan paralinguistic sebagai aspek koteksnya, bidang budaya dan aspek kehidupan manusia. Unsur utama tersebut akan dicari bagaimana nilai dan norma kearifan local tersebut, bentuk revitalisasi dan pelestarian budaya untuk membantu penguatan karakter masyarakat seutuhnya.

Bangsa Indonesia memiliki kekayaan masa lalu yang luar biasa. Warisan budaya Indonesia seolah tak pernah habis sepanjang masa, dan selalu membuat takjub dunia. Melalui kearifan lokal atau local wisdom menjadi kontrol dalam mempersiapkan mental generasi muda menjadi lebih baik dan lebih sejahtera. Maka, slogan remembering the past, understanding the present, and preparing the future with sustainability dapat menjadi salah satu tolok ukur dalam mempersiapkan mental generasi muda menjadi lebih baik. Nilai dan norma budaya yang dapat diterapkan dalam menata kehidupan sosial merupakan bentuk local wisdom harus terus dikaji secara mendalam guna membangun karakter dan 
identitas masyarakat. Salah satu bentuk tradisi Jawa yang sampai sekarang masih dipertahankan adalah tradisi Meron di Sukolilo Kabuaten Pati.

Upacara tradisi meron salah satu ritual yang dilaksanakan setiap bulan maulud, tradisi ini dilakukan oleh masyarakat desa Sukolilo Kabupaten Pati yang bertujuan untuk memperingati hari kelahiran Nabi Muhammad SAW. Tradisi ini mirip dengan Grebek Maulid (Sekatenan) yang ada di Kraton Yogyakarta dan Kraton Surakarta.Tradisi meron ini dilaksanakan berdasarkan perhitungan penanggalan aboge(alip rebo wage).

Dalam sejarah peradaban Islam peringatan Maulid Nabi sudah diperingati sejak lima abad yang lalu. Kegiatan memperingati hari kelahiran Nabi Muhammad SAW dilaksanakan di berbagai penjuru dunia, yang berjalan secara terus-menerus hingga berkembang menjadi tradisi.

Begitu juga dengan tradisi Meron. Awal mula diakan sebagai wujud rasa syukur atas kemenangan para prajurit Mataran yang berhasil membebaskan tanah di daerah kabupaten Pati yang bertepatan dengan kelahiran Nabu Muhammad SAW. Tradisi Meron telah banyak diteliti dari berbagai aspek, terutama dari kajian religi. Tetapi belum banyak dipahami nilai-nilai estetis dari local wisdom suatu daerah sebagai kekayaan nusantara yang harus dijaga dan dikembangkan. Oleh karena itu, dalam penelitian ini akan dijelaskan bagaimana pemaknaan simbol-simbol budaya dan spiritual dari tradisi Meron di Sukolilo Kabupaten Pati.

\section{Metode Penelitian}

Jenis penelitian ini merupakan penelitian kualitatif dan dalam pengembangannya menggunakan metode desktiptif fenomenolois. Pengambilan data dalam penelitian studi lapangan ini menggunakan metode wawancara dan dokumentasi, dilanjutkan dengan teknik rekam dan catat. Objek penelitian ini adalah simbol-simbol budaya yang digunakan dalam tradisi Meron masyarakat Sukolilo Kabupaten Pati.

Sumber data utama yang digunakan dalam penelitian ini atau data primer adalahdata yang diperoleh melalui observasi dan wawancara. Wawancara utama dalam penelitian leksikon tradisi Meron ini dilakukan kepada informan kunci. Informan kunci adalah pemuka tradisi Meron di Sukolilo Kabupaten Pati yang masih merupakan keturunan langsung dari Demang Sukolilo yang bertindak sebagai 
informan kunci. Selanjutnya, sebagai narasumberberasal dari masyarakat Sukolilo yang mengetahui atau terlibat langsung dalam pelaksanaan tradisi Meron.

\section{Pembahasan}

Berdasarkan penelitian yang telah dilakukan terhadap upacara tradisi meron di desa Sukolilo Kabupaten Pati, diperoleh simbol-simbol khas yang terkandung dalam prosesi tradisi tersebut. TradisiMeron sebagai bukti kearifan lokal yang masih terjaga sampai saat ini. Bentuk kearifan lokal yang sarat akan makna filosofis nilainilai budaya yang disiratkan melalui simbol-simbol budaya dalam wujud sesaji. Kemegahan Sesaji Meron memiliki merupakan cerminan masyarakat Jawa khususnya Sukolilo dalam meneladani nilai-niai budaya. Berikut akan dipaparkan wujud dan simbol-simbol budaya tradisi Meron:

\section{Meron}

BerdasarkanPrawiroatmodjo (1981) nama Meron diambil dari bahasa Jawa Kawimerong yang secara leksikal mempunyai arti (1) ngamuk yang direfleksikan dalam perang masal. Karena sebelum diadakan meron, sedang berlangsung perang masal. Arti (2) meron berarti emper atau serambi, sebab sebelum di arak gunungan meron dipajang di jejer di serambi atau kediaman pemiliknya. Dalam bahasa Arab, Meron berarti Mi'raj yang berarti kemenangan.

Adapula yang menyebutkan bahwa namameron diambildari kata meru dari bahasa Jawa Kuna (Kawi). Kata meru berarti sebagai 'gunung', pengertian ini berhubungan bentuk arsitektur sesaji Meron yang berbentuk gununganmenyerupai gunung atauyang oleh masyarakat setempat disebut dengan gunungan. Dalam kirata basa (Jawa) juga bermakna Me: Rame, ron: tiron-tiron, sehingga meron diartiken sebagai rame tiron.

Selain berasal dari kedua kata di atas yang diadopsi dari bahasa Jawa Kuno (Kawi), berdasar sumber dari informan kunci disebutkan bahwa asal-usul penamaan meron diadaptasi dari bahasa Arab mi'roj yang dihubungkan dengan peristiwa isro' mi'roj Nabi Muhammad. kata mi'roj tersebut mengandung arti 'naik'. Nilai filosofis tersebut dimaknai sebagai symbol bahwa manusia harus lebih meningkatkan keyakinan atas Tuhannya. Dan yakin bahwa ada kematian di mana akan ada saat manusia akan bertemu dengan Tuhannya. Tuhan selalu disimbolkan dengan zat yang 
ada di atas. Manifestasi dari keesaan Tuhan juga direpresentasikan dalam arsitektur gunungan sesaji, di mana puncak dari sesaji tersebut berbentuk kerucut dan meruncing ke atas. Hal tersebut juga memiliki simbol bahwa semakin tinggi tingkat keimanan seseorang, maka akan semakin sedikit pula ketertarikannya terhadap gemerlapan dunia. Oleh karena itu, harapan bahwa upacara tradisi meron dapat menjadi sarana naiknya keimanan, naiknya persatuan antar sesama masyarakat dan lain sebagainya.

Aboge

Abogemerupakan sistem perhitungan kalender Jawa. Merupakan akronim dari kataalip. Dipercaya masyarakat Sukolilo sebagai awal angka untuk menyebut urutan pertama. Alip dari bahasa Arab 'alif' merupakan refleksi dari keEsaan Tuhan.Huruf alif juga mempunyai bentuk lurus yang memfilosofikan Siratal Mustaqim 'jalan yang lurus'.Makna yang diyakini oleh masyarakat Sukolilo bahwa dalam mengawali tahun pertama dan seterusnya semoga selalu mendapat perlindungan dan keberhakan dari Tuhan. Lalu bopada kata Aboge merujuk pada rebo dalam bahasa Jawa yang artinya 'Rabu' pada nama-nama hari baik dalam kalender Jawa dan Masehi. Dan ge pada kata Aboge dari kata wage yang merupakan nama pasaran dalam bahasa Jawa.

Sistem perhitungan kalender Jawa aboge pada setiap tahunnya mempunyai nama-nama tersendiri yang telah dirumuskan secara turun-temurun dalam periode satu windu (8 tahun). Adapun nama-nama tahun tersebut meliputi, alip yangartinya ada-ada (mulai berniat), ehe memiliki arti tumandang (melakukan), jimawal artinya gawe (pekerjaan), ze adalah lelakon (proses, nasib), dal artinya urip (hidup), be memiliki arti bola-bali (selalu kembali), wawu artinya marang (ke arah), dan jimakir artinya suwung (kosong). Sedangkan urutan perhitungan harinya dalam satu windu tersebut terdiri dari setu legi, kemis legi, senen kliwon, jemuwah wage, rebo wage, ngat pon, jemuwah pon, selasa pahing.

Perhitungan pelaksanaan tradisi meron dengan penanggalan aboge telah disinggung pada bab sebelumnya, contoh perhitungannya yaitu pada pelaksanaan Meron tahun 2017. Dalam kalender Hijriyyah Maulid Nabi Muhammad SAW jatuh pada tanggal 1 Desember 2017, tepatnya pada hari jumat kliwon. Hari Jumat kliwon tidak termasuk dalam rumusan hari penanggalan aboge yang telah ditetapkan, untuk 
itu pelaksanaan tradisi meron di Sukolilo Kabupaten Pati pada tahun 2017 nantinya diadakan pada hari berikutnya yaitu sabtu legi yang jatuh pada tanggal 2 Desember sesuai dengan perhitungan kalender aboge.

Pelaksanaan Meron dengan kalender Jawa sistem Aboge sampai sekarang masih dipertahankan oleh masyarakat Sukolilo Kabupaten Pati. Hal ini menunjukkan bahwa masyarakat Sukolilo masih menjaga kearifan lokal sebagai guidens dalam menjalankan ritual atau upacara adat yang diyakininya. Selain menjunjung tinggi dan menghormati nilai-nilai budaya leluhurnya. Dalam sistem kebudayaan juga dikenal dengan teknologi, sistem penanggalan Aboge yang dipercaya masyarakat Sukolilo sebagai bukti bahwa walaupun secara materiil masyarakat Sukolilo jauh dari kota Metropolitan, tetapi dalam keteguhan menjalankan keyakinannya mereka mampu menciptakan sistem penanggalan yang luar biasa. Dan itu sebagai bentuk intelligence local wisdom masyarakat pesisir Jawa.

\section{Ancak}

Dalam perspektif antropologis, ancak sebagai lambang dari kerukunan dan ketentraman. Ketiga tingkatan dalam ancak mengandung filosofi kepada masyarakat bahwasanya untuk mencapai kehidupan yang mulia, rukun dan tentram harus berlatih untuk menyeimbangkan cipta, rasa dan karsa.Dalam tradisi meron yang dilaksanakan sebagai acara keagaamaan, ketiga komponen tersebut (cipta, rasa dan karsa) merupakan gambaran tingkatan dalam beragama, yang meliputi islam, iman dan ihsan.

Cipta dapat diartikan sebagai keinginan menciptakan sesuatu (tahap awal berada dalam pikiran). Dibutuhkan kekuatan visualisasi atau daya cipta terhadap suatu keinginan. Tahap berikutnya adalah rasa atau merasakan sesuatu yang tercipta dalam pikiran. Sesuatu yang kita ciptakan dalam pikiran seolah-olah sudah terwujud dan kehadirannya dapat dirasakan. Setelah sesuatu tersebut tercipta dalam pikiran yang disusul dengan merasakan hasil ciptaannya, maka dilanjutkan dengan karsa atau berupaya mewujudkan keinginan tersebut secara nyata, sehingga dapat dilihat, disentuh, dan dimanfaatkan (berdaya guna). 
Ancak dibuat secara tradisional oleh masyarakat Sukolilo dengan berbahan dasar kayu. Ancak atau ancangan dalam bahasa Jawa memiliki nilai filosofi sebagai fondasi. Fondasi sebagai makhluk individu dan bermasyarakat. Bahwa, sebagai makhluk individu, manusia hendaknya memperkuat tingkat keimanan, keyakinan, dan menjalankan perintah Tuhan dengan baik. Dengan keyakinan dan keimanan yang baik, maka dalam berhubungan dengan manusiapun akan terjalin dengan baik.

Hal ini menunjukkan bahwa masyarakat Sukolilo mampu memanfaatkan lingkungannya. Meskipun dalam penggunaannya, ancak tidaklah lagi digunakan dalam kebutuhan sehari-hari, melainkan hanya digunakan sebagai tempat sesaji dalam pelaksanaan upacara tradisi meron atau upacara tradisi yang lainnya seperti halnya sedekah bumi. Hal ini terjadi seiring dengan perkembangan zaman dimana telah tersedia peralatan sehari-sehari yang lebih praktis dan mudah untuk didapatkan.

\section{Iber-Iber}

Sesuai dengan Prawiroatmodjo (1981) kata iber-iber bermakna'terbang'.Kata iber dapat dimaknai sebagai rejeki tidak datang secara tiba-tiba, tetapi harus dikejar dengan usaha dan doa. Pada dasarnya iber dalam tradisi Meron direfleksikan dalam bentuk 'nasi kenduri yang dipikul dan ditempatkan dalam wadah berbentuk persegi yang dibuat dari bambu'. Dalam pelaksanaan Meron, yang wajib menyiapkan iberiber adalah perangkat desa. Sebagai bentuk syukur atas berkah kekayaan alam dari tanah bengkok yang mereka dapatkan selama menjabat. Dan hasil alam tersebut dikembalikan ke warga untuk dinikmati bersama. Para pemikul iber-iber membentukbarisan memanjang tanpa terputus.Barisan memanjang secara filofosis juga memiliki makna bahwa keberkahan alam tidak akan terputus apabila orang yang mampu dalam hal ini perangkat desa sadar dengan kewajiban untuk berbagi.

Makanan yang ada dalamiber-iber dipercayamengandung berkah bagi siapapun yang memakannya. Oleh karena itu, iber-iber menjadi bahan rayahan 'rebutan' bagi masyarakat bahkan tak jarang habis terlebih dahulu ketika proses arak-arakan baru dimulai. Berdasarkan peristiwa rayahan tersebut, maka nasi kenduri tersebut diibaratkan miber 'terbang'. Terbang dalam hal ini adalah makanan yang diperebutkan oleh masyarakat saling berserakan di atas kepala mereka yang 
diibaratkan seperti makanan yang ngiber-iber. Iber-iber ini dibuat sebagai simbolisasi kepedulian para pemimpin desa kepada rakyatnya.Bentuk iber-iber ini secara fisik menyerupai timbangan yang dapat dianalogikan sebagai upaya penyeimbangan pelayanan yang diberikan para perangkat desa kepada masyarakat yang dipimpin.

\section{Mancungan}

Mancungan berasal dari kata mancungyang berartikan seludang (kulit pemalut mayang pinang atau kelapa), ditemukan pula kata mancung(an) yang berarti sebagai cara memakai ikat kepala (sudutnya bertemu di dahi) (Prawiroatmodjo, 1981). Mancungan dalam tradisi meron adalah bagian dari gunungan sesaji dalam Meron yang terbuat dari kertas yang dibuat meruncing menyerupai ujung tombak.

Filosofi katamancungan adalah simbolisasi dari tombak. Simbol tombak tersebut sebagai pengingat yang dihubungkan dengan upaya pertahanan diri agar masyarakat senantiasa mampu mengendalikan hawa nafsu dan melawan segala bentuk perbuatan tercela dengan menambah keimanan dan melakukan hal-hal terpuji sebagai senjatanya.

\section{Once}

Kata once adalah digubah, dianggitatau dikarangkan (Prawiroatmodjo, 1981), dalam tradisi meron, once adalah salah satu bahan penyusun sesaji yang terbuat dari ketan yang sudah dipotong kecil-kecil kemudian dirangkai dengan benang dan dipasang menutup gunungan. Once dibuat sebagai lambang dari sekar melati rinonce (untaian bunga melati), yang dalam budaya Jawa rangkaian bunga melati ini mengandung beberapa simbol di antaranya sebagai simbol kesucian dan ketulusan. Kesucian disini merupakan penggambaran kebersihan hati yang harus senantiasa dijaga dengan berusaha melaksanakan amar ma'ruf nahi munkar yaitu melaksanakan halhal baik dan menjauhi hal-hal yang buruk. Selain hal di atas, once yang melambangkan melati juga dapat dimaknai sebagai ungkapan mlakune ati-ati. Bahwa dalam menjalani kehidupan harus melangkah dengan hati-hati agar terhindar dari hal yang kurang baik.

\section{Sega Ruruh}


Kata sega ruruh berasal dari bahasa bahasa Jawa disebutkan bahwa kata ruruh sendiri mempunyai artian tenang (Prawiroatmodjo, 1981).Sega ruruh yang dimaksudkan dalam tradisi meron merujuk kepada nasi kenduri yang digunakan sebagai isian ancak yang berada pada tingkatan paling bawah. Oleh karena itu, dapat disimpulkan bahwa kata sega ruruh dalam tradisi Meron tidak mempunyai keterkaitan atau dengan kata lain tercipta makna baru.

Sega ruruh dari segi budaya memiliki makna lambang penyucian lahir dan batin dengan tujuan memperoleh kehidupan yang lebih baik. Penamaan sega ruruh mengimplementasikan sifat santun yang seharusnya dimiliki masyarakat ketika mengambil atau memakan sesaji tersebut. Pada praktik sesungguhnya, perilaku masyarakat dalam mengambil sega ruruh maupun sesaji yang lain belum mencerminkan makna yang terkandung dari sega ruruh itu sendiri.

\section{Simpulan}

Berdasarkan analisis kearifan lokal tradisi Meron masyakarat Sukolilo di Kabupaten Pati, dapat disimpulkan bahwa bentuk tradisi budaya local wisdom Meron berkembang dalam bentuk penyebutan ungkapan tradisional yang terealisasi dalam pertunjukan ritual upacara adat dan pesta adat, pelestarian teknologi tradisional dalam hal ini melalui arsitektur gunungan sesaji. Sedangkan fungsi dari tradisi budaya tersebut berupa 1) usage atau cara melakukan upacara atau ritual, 2)folkways atau kebiasaan dalam menjalani tradisi leluhur yang masih dilestarikan, 3) norm atau norma berkaitan dengan adat yang diketahui dan ditaati oleh masyarakat.

\section{Daftar Pustaka}

Duranti, Alessandro. 1997. Linguistic Anthropology. United Kingdom: Cambridge University Press.

Jaourdan, Cristine and Kevin Tuite. 2006. Language, Culture, and Society. New York: Cambridge University Press.

Prawiroatmodjo. 1981. Bausastra Jawa-Indonesia (Edisi Kedua). Jakarta: Gunung Agung. 
Sibarani, Robert. 2013. Pendekatan Antropolinguistik dalam Menggali Kearifan Lokal Sebagai Identitas Bangsa. Proceeding International Conference on Indonesian Studies. FIB, Universitas Indonesia, Jakarta.

Sudaryanto. 2015. Metode dan Aneka Teknik Analisis Bahasa. Yogyakarta: Sanata Dharma University Press. 